\title{
Research of Fault-tolerant Control Strategy for Cascaded STATCOM
}

\author{
Xiaodong Yang ${ }^{1}$, Zhenglong Xia ${ }^{2}$, Wenyong Duan ${ }^{1}$, Guowen $\mathrm{Hu}^{1}$ \\ ${ }^{1}$ School of Electrical Engineering, Yancheng Institute of Technology \\ Yancheng, Jiangsu 224000, China \\ ${ }^{2}$ School of Electrical Engineering and Automation, Jiangsu Normal University \\ Xuzhou, Jiangsu 221000, China \\ 24661883@qq.com
}

\begin{abstract}
The fault-tolerant control strategy method is studied for the H-bridge cascaded multilevel STATCOM under module fault in this paper. The influences of module fault to each part of STATCOM control system are analyzed. The method of phase-to-phase capacitor voltage balance control, one phase capacitor voltage balance control and PWM control with fault-tolerant function are then introduced.. Finally, an eight cascaded multilevel STATCOM is used to test this method both in simulation and experimentation. The results show that the fault-tolerant control strategy can effectively guarantee the output voltage amplitude and low harmonic content, and improve the reliability and stability of the STATCOM system.
\end{abstract}

Keywords: Cascaded STATCOM, H-bridge, Module redundancy, Fault-tolerant control

\section{Introduction}

Cascaded H-bridge multilevel static synchronous compensator (STATCOM) are widely used in reactive compensation and harmonic suppression because of their advantages such as modularity, high power capacity, good harmonic characteristic, and easily realized redundancy. The reliability of the STATCOM is directly related to the safe operation of the power grid.

Due to the limited capacity of a single power switch, we usually only increase the number of cascade stage to achieve high power and high voltage output, that it will need a large number of power switching devices. For example, the $\pm 200 \mathrm{Mvar}$ STATCOM in China Southern Power Grid Dongguan substation have 26 stages in series in each phase $[1,2]$. It has 312 power switches in three phases. Each of these devices is a potential failure spot and it will dramatically reduce the reliability of the system. When it fails and no fault-tolerant control strategy to implement, the failure will get more serious, and fault protection shutdown will be happen, that will cause serious harm to power grid and electric appliance. Through reconstructing both the software and hardware structures of the system upon fault-tolerant control strategy and fault isolation device can ensure that the system continues to operate safely without any reduction or partly reduction in performance indicators. So appropriate fault-tolerant control strategies can effective improve the reliability of the STATCOM system[3]. Therefore, research on fault-tolerant control strategies of the STATCOM system has important significance both in theory and practical value.

From the structure characteristics of cascade STATCOM system can be seen that the most simple and effective method to achieve fault-tolerant capabilities is redundancy. The present redundancy methods are system redundancy, module redundancy and switch 
redundancy. The module redundancy is the most popular scheme because of its advantages both in fault-tolerant cost and fault diagnosis difficulty.

Module redundancy will increase one or two redundant power module in each phase. The redundant power module will be bypassed or all power modules work derating when the system in normal operation. When the fault occurs, the fault power module will be bypassed and the redundant power module will run or all power modules run in rated condition [4-9].

If the power switch fault occurs, it will necessary to be isolate or bypassed, and to ensure the normal work of the other parts. According to different isolation object, the fault isolation can be divided to symmetric module isolation, fault module isolation and switch tube isolation [10].

Symmetric module isolation is that the fault module and two modules in the same position in other phases will be bypassed at the same time. The capacitor voltage of remaining modules in the fault phase will be improved to ensure the normal work of the system. It is the simplest method to achieve the fault-tolerant control strategy. Disadvantage is that two normal modules will be waste

Switch tube isolation is that only the fault power switch will be isolated and the other normal power switches in fault module will be worked to improve the fault-tolerant abilities of the system. Because of the difficulty of fault diagnosis and additional isolation devices, this method is usually used for the system with little power switches such as the three-phase bridge voltage source inverter. When it used for the convert moth than two cascades, the cost is too high.

Fault module isolation is that only the fault module will be isolated. It is easy to achieve fault diagnosis and the cost is acceptable. There are mainly two fault-tolerant control strategies for this isolation method: the neutral-shift technique and the space vector decomposition method [11]. Because of that the converter star point can float, the neutral-shift technique can get the three-phase equilibrium line voltage by adjusting the phase angle of the three-phase output voltage. For STATCOM system, the three-phase equilibrium phase voltage is what we need. So the neutral-shift technique is not suitable for the STATCOM system. The space vector decomposition method is suitable for the system with less than three cascades, for the space vector will be more difficulty synthesized with the increase of number of the cascade.

Integrated the advantages and disadvantages of the above mentioned, the faulttolerant control strategies of the cascaded STATCOM system based on module redundancy and fault module isolation are proposed in this paper.

\section{Experiment Platform}

In this paper, a $6 \mathrm{KV}$ eight cascaded STATCOM device is investigated. The circuit theory is presented in Figure 1. Each phase has eight power modules connected in series. Three phases build a neutral point on one side, and connect to the power grid through LCL filter on the other side.

The N+1 module redundancy and fault module isolation methods are used in this paper. The rated reference capacitor voltage value is set to $800 \mathrm{~V}$. In normal condition, all power modules are in a derating running state, and the reference capacitor voltage value is set to $700 \mathrm{~V}$. When the fault is monitored by the fault diagnosis system, the fault module will be bypassed and its driving signal will be locked. Then the reference capacitor voltage of other seven non-fault modules will back to the rated value to ensure the amplitude of the output phase-voltage. The reference capacitor voltage of fault phase is set to $800 \mathrm{~V}$, and other two phases remained to $700 \mathrm{~V}$. 


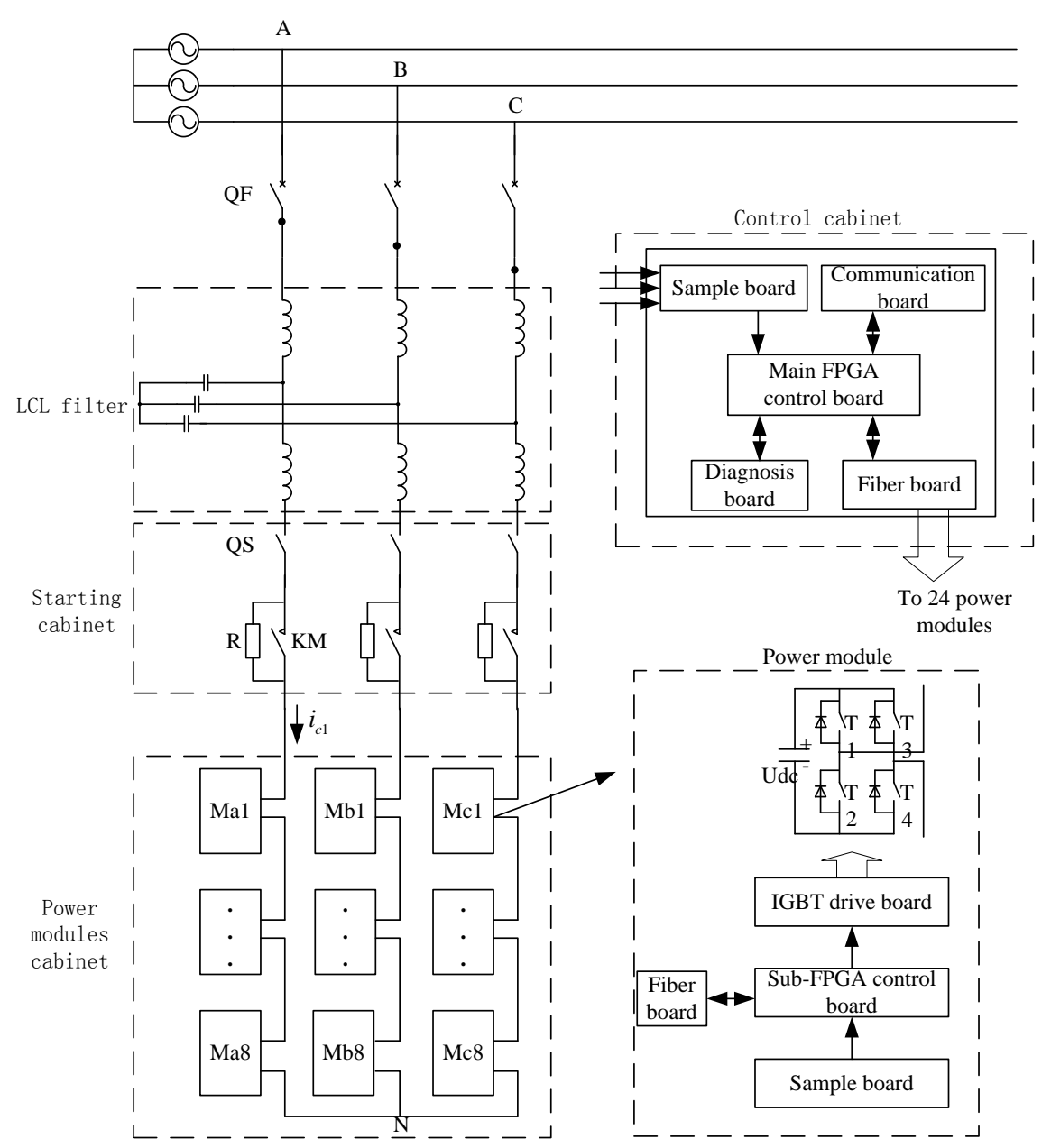

Figure 1. General Structure of the Experiment Platform

\section{Fault-Tolerant Control Strategy}

The general structure of the control strategy is showed in Figure 2. It includes command current calculation, decoupling control, LCL damping control, capacitor voltage balance control for different phase, capacitor voltage balance control for one phase, PWM control.

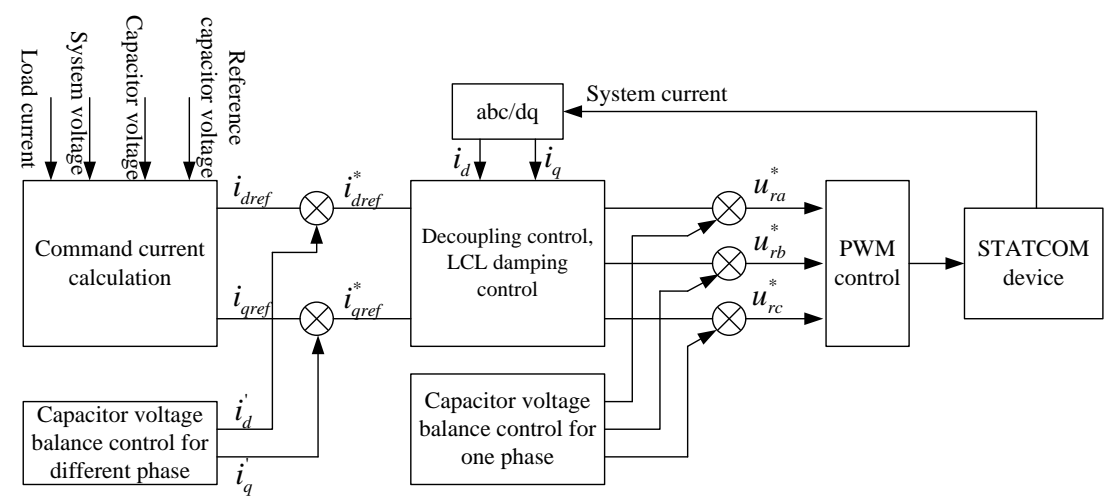

Figure 2. General Structure of the Control Strategy 


\subsection{The influence of Module Fault on Each Control Section}

\subsubsection{The Influence on Command Current Calculation}

The command current calculation can be divided into active current command and reactive current command as shown in Figure 3. It also shows that the only controllable variable is the total reference capacitor voltage, which is defined as $U_{d c r e f}$. In normal condition, as the reference voltage value of one power module is $700 \mathrm{~V}$, so the value of $U_{\text {dcref }}$ is

$U_{\text {dcref }}=(N+1) * 700 * 3=16800 \mathrm{~V}$

When one power module is failure, the reference voltage value of fault phase is set to $800 \mathrm{~V}$, and the value of $U_{\text {dcref }}$ is

$$
U_{\text {dcref }}=N * 800+(N+1) * 700 * 2=16800 \mathrm{~V}
$$

For the value of $U_{\text {dcref }}$ is not influenced by the fault as shown in (1) and (2), the section of command calculation needn't to be adjusted.

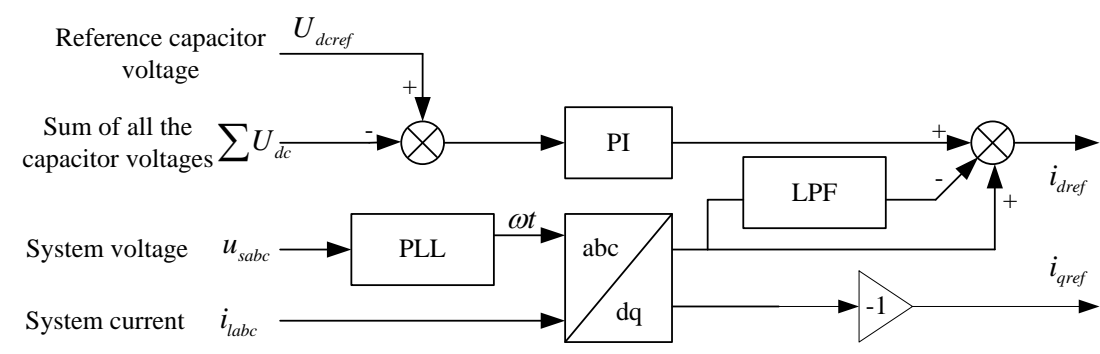

Figure 3. Calculation of the Command Current

\subsubsection{The Influence on Capacitor Voltage Balance Control}

Capacitor voltage balance control includes capacitor voltage balance control for different phase and capacitor voltage balance control for one phase. When fault occurs, the capacitor voltage balance will be broken, because the reference capacitor voltage of fault phase is increased. So, the section of capacitor voltage balance control for different phase must be adjusted. The section of capacitor voltage balance control for fault phase also need to be adjusted, as the number of running power modules in fault phase is decreased

\subsubsection{The influence On Decoupling Control and LCL Damping Control}

As shown in Figure 2, the input and output of controller are command current and three phase reference modulation wave. When the fault occurs, only the input and output superposition control value need to be adjusted, and it have no influence on internal control algorithm of controller. Therefore, the section of decoupling control and LCL damping control needn't to be adjusted.

\subsubsection{The Influence on PWM Control}

In cascaded STATCOM, the commonly used PWM control methods are carrier disposition PWM, phase shift carrier PWM and space vector PWM. No matter the number of triangular carrier, the angle of phase shift, the number of disposition based on carrier method or the number of basic vectors based on space vector PWM are directly related 
with the number of cascaded. When fault occurs, the PWM control must be adjusted for decreasing of cascaded number of fault phase.

\subsection{Capacitor Voltage Balance Control Strategy with Fault-Tolerant}

\subsubsection{Capacitor Voltage Balance Control for Different Phase with Fault-Tolerant}

There are two methods to implement capacitor voltage balance control for different phase. One is to superpose a tiny voltage control variable on the signal of output reference modulation wave and another is to superpose a tiny current control variable on the signal of output command current. To superpose a tiny current control variable for example, the average value of three-phase capacitor voltage is defined as $\bar{U}_{d c} \cdot \bar{U}_{d c a}, \bar{U}_{d c b}$ and $\bar{U}_{d c c}$ are the average value of capacitor voltage of each phase. So, the capacitor voltage deviation of phase A is $\Delta U_{d c a}=\bar{U}_{d c}-\bar{U}_{d c a}$. The DC command current of phase A $I_{a}^{*}$ is obtained via PI regulator. The AC command current of phase A $I_{a p}^{*}$ is obtained by DC/AC converter. The superposed current control variable is then obtained by $d p / a b c$ transform. Figure 4 is the specific process.

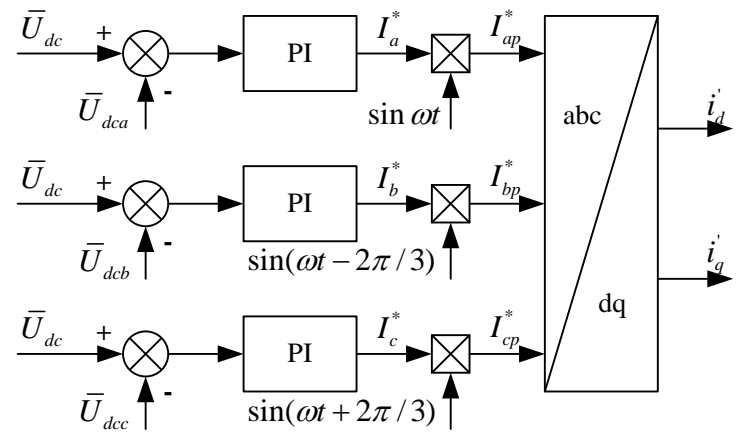

Figure 4. Capacitor Voltage Balance Control For Different Phase

The reference capacitor voltage value of fault phase is changed when fault occurred. So the input of fault phase in Figure 4 will be changed as $U_{d c}$, then the fault phase will not participate in the capacitor voltage balance control for different phase. The different phase balance control will just for the other two normal phases, and the input will be changed as $U_{d c n}$. The Average arithmetic module and distribution module is proposed in Figure 5 to implement the fault-tolerant control.

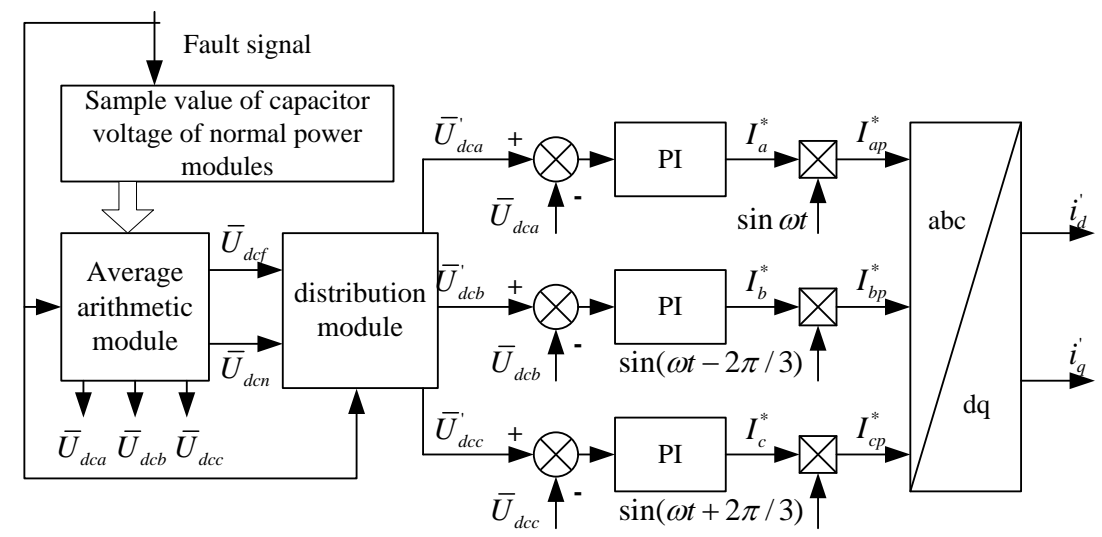

Figure 5. Capacitor Voltage Balance Control For Different Phase with Fault Tolerance 
By using fault diagnosis result and each capacitor voltage sample value, the average arithmetic module can figure out the capacitor average value of each phase, the capacitor average value of fault phase and the capacitor average value of normal phase, which are defined as $\bar{U}_{d c a}, \bar{U}_{d c b}, \bar{U}_{d c c}, \bar{U}_{d c f}, \bar{U}_{d c n}$. The new input value will be changed as $\bar{U}_{d c a}^{\prime}$, $\bar{U}_{d c b}^{\prime}$ and $\bar{U}_{d c c}^{\prime}$ by using distribution module.

In normal condition, we obtain the following equation:

$\bar{U}_{d c a}^{\prime}=\bar{U}_{d c b}^{\prime}=\bar{U}_{d c c}^{\prime}=\bar{U}_{d c n}=\left(\bar{U}_{d c a}+\bar{U}_{d c b}+\bar{U}_{d c c}\right) / 3$

If one power module of phase A fails, the following equations will be obtained

$\bar{U}_{d c a}^{\prime}=\bar{U}_{d c f}=\bar{U}_{d c a}$

$\bar{U}_{d c b}^{\prime}=\bar{U}_{d c c}^{\prime}=\bar{U}_{d c n}=\left(\bar{U}_{d c b}+\bar{U}_{d c c}\right) / 2$

If single power module fault occurred in phase $\mathrm{A}$ and $\mathrm{B}$, then

$\bar{U}_{d c a}^{\prime}=\bar{U}_{d c b}^{\prime}=\bar{U}_{d c f}=\left(\bar{U}_{d c a}+\bar{U}_{d c b}\right) / 2$

$\bar{U}_{d c c}^{\prime}=\bar{U}_{d c n}=\bar{U}_{d c c}$

If single power module fault occurred in each phase, then

$\bar{U}_{d c a}^{\prime}=\bar{U}_{d c b}^{\prime}=\bar{U}_{d c c}^{\prime}=\bar{U}_{d c f}=\left(\bar{U}_{d c a}+\bar{U}_{d c b}+\bar{U}_{d c c}\right) / 3$

\subsubsection{Capacitor Voltage Balance Control for One Phase with Fault-Tolerant}

As shown in Figure 6, the No m power module of phase A's capacitor voltage is defined as $U_{d c a m}$. There are a slight deviation between $U_{d c a m}$ and $\bar{U}_{d c a}$, which is expressed as $\Delta U_{d c a m}=\bar{U}_{d c a}-U_{d c a m}$. For one phase balance, the offset voltage $U_{\Delta a m}$ of No $\mathrm{m}$ power module can obtained by using PI regulator and DC/AC converter.

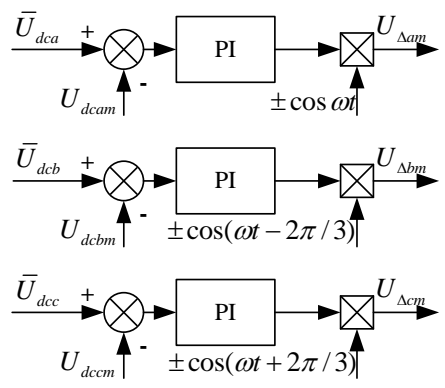

Figure 6. Capacitor Voltage Balance Control For One Phase

The sign $U_{\triangle a m}$ is control by STATCOM absorbing or issuing reactive power, that is

$U_{\Delta a m}=\left\{\begin{array}{l}K \cdot \Delta U_{d c a m} \cos \omega t, \quad p^{*}>0 \\ -K \cdot \Delta U_{d c a m} \cos \omega t, \quad p^{*}<0\end{array}\right.$

Where $p^{*}=u_{c a} * i_{c a}, u_{c a}$ is the output voltage, $i_{c a}$ is the output current.

When fault occurs, the average capacitor voltage value of fault phase will not contain the fault power module. The average arithmetic module is proposed in one phase balance control to implement the fault-tolerant control as shown in Figure 7. 


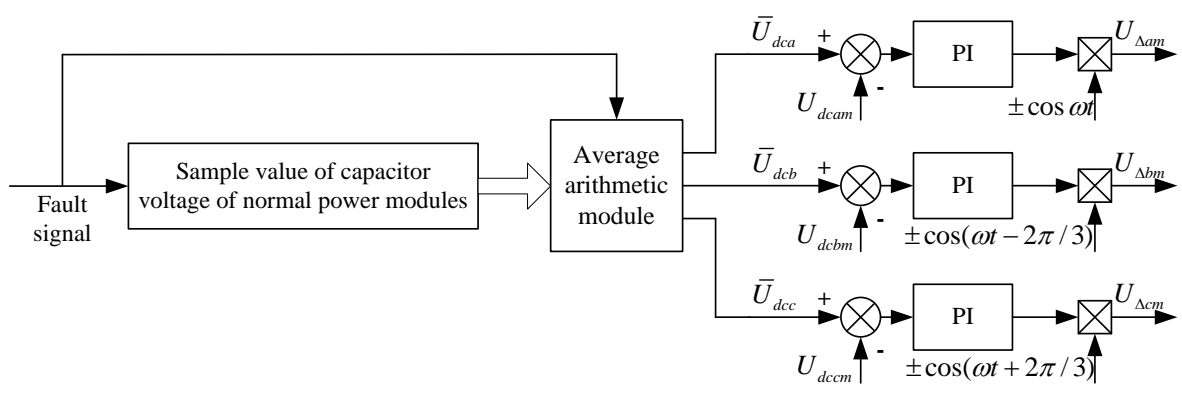

\section{Figure 7. Capacitor Voltage Balance Control For One Phase with Fault} Tolerance

\subsection{PWM Control Strategy with Fault-Tolerant}

The carrier phase shift PWM (CPSPWM) method is used in this paper. With the strategy of single polarity double frequency, the triangular carrier phase shift time between adjacent power modules is $T_{c} / 2(N+1)=T_{c} / 16$, where $T_{c}$ is the period of triangular carrier, $N+1$ is the cascade numbers with one redundant module.

According to the sampling theorem, each power module must be sampled at least in each triangular carrier wave peak and trough. For eight cascades, the sample period $T_{s}$ is equal to the shift time $T_{c} / 16$. Take the No 4 power module fault for example, the pulse sequences of pre- and post-fault are showed in Figure 8 and Figure 9.

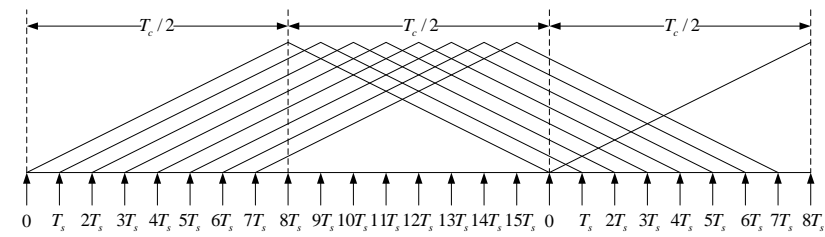

Figure 8. Pulse Sequences of Eight Power Modules before the Fault Occurrence

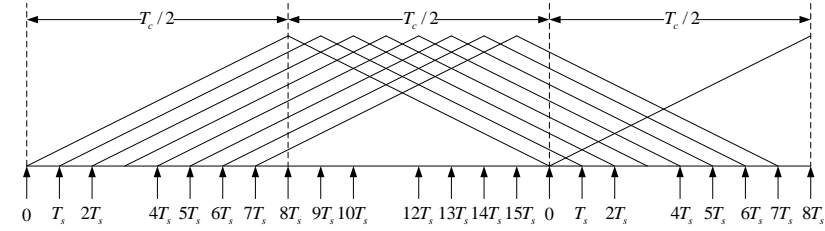

\section{Figure 9. Pulse Sequences of Seven Power Modules after the Fault Occurrence}

In normal condition, the sampling interval between each adjacent power modules is $T_{s}$. When No 4 power module fault occurs, the sampling interval between No 3 and No 5 power module is changed as $2 T_{s}$. For the different sampling interval, the harmonic content for the output voltage of STATCOM will be increased. So the PWM strategy must be adjusted to ensure the same sampling interval in normal power modules. We can change the sample period or the carrier period to obtain the same sampling interval. For the uniform sampling interval is used for the A/D converter, the command current refresh and the PWM drive signal generation, so we can only change the triangular carrier period. It can be changed as $T_{c}^{\prime}=T_{c}(N+1-m) /(N+1)$, where $m$ is the fault module numbers. The Figure 10 shows the changed pulse sequences with $m=1$. 


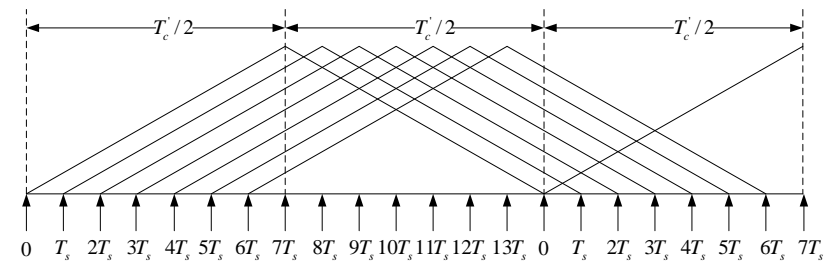

Figure 10. Pulse Sequences of Seven Power Modules after the Carrier Cycle Adjustment Experimental Validation

\section{Experimental Validation for Fault-Tolerant Control Strategy}

The fault signal is simulated by an outer knob. The main FPGA controller will execute the fault-tolerant program will monitoring the fault signal. The workflow and the experiment conditions of the fault-tolerant control are shown in Figure 11 and Table 1.

Table 1. The Experiment Conditions of the Fault-Tolerant Control

\begin{tabular}{|l|l|}
\hline Device & Work conditions \\
\hline Compensate STATCOM & To absorb the capacitive current \\
\hline Load STATCOM & $\begin{array}{l}\text { To absorb the inductive current, and } \\
\text { the value is } 150 \mathrm{~A}\end{array}$ \\
\hline Time of fault & Controlling by an outer knob \\
\hline Scope monitoring point & Channel 4 : output voltage $u_{a n}$ \\
\hline
\end{tabular}

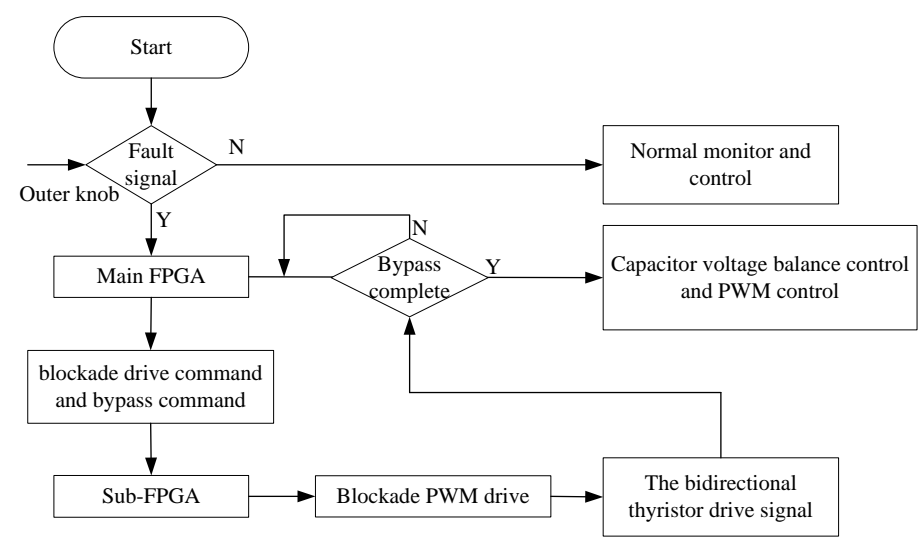

Figure 11. Workflow of the Fault-Tolerant Control

The output voltages of STATCOM before and after the fault-tolerant control are shown in Figure 12 and Figure 13. The figure shows that the level numbers of output voltage is changed from 17 to 15 , and the duration of the highest level is increased. 


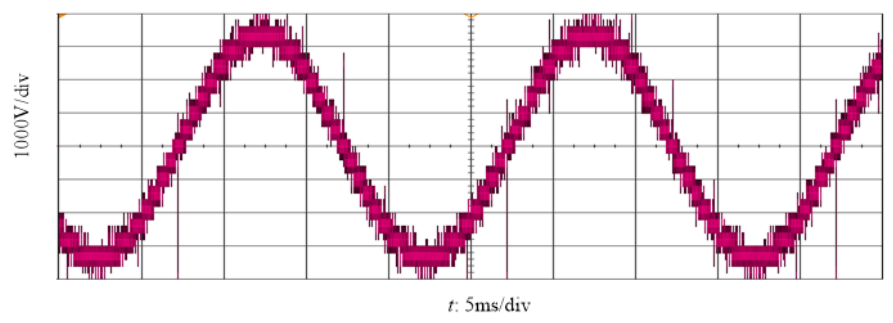

Figure 12. Waveform of $u_{a n}$ under Normal Condition

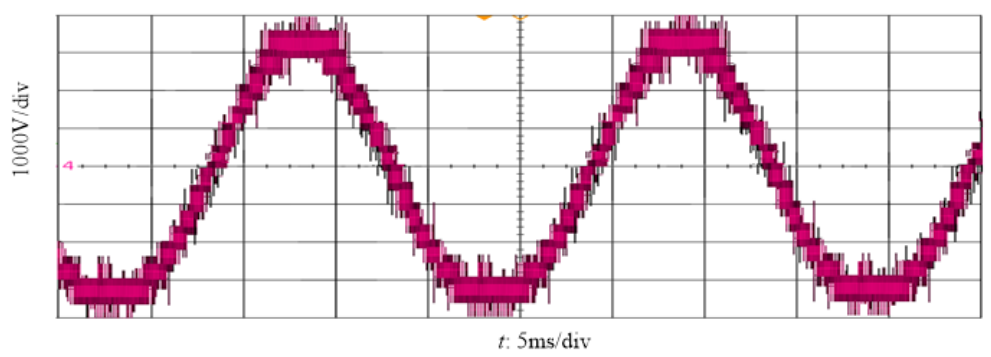

Figure 13. Waveform of $u_{a n}$ under Fault-Tolerant Control

Waveforms of capacitor voltages of all power modules in phase A are draw by using industry computer software. As shown in Figure 14, when the fault-tolerant control strategy executing, the capacitor voltage of normal power modules is changed from $700 \mathrm{~V}$ to $800 \mathrm{~V}$ and keep in a stable value. The capacitor voltages of phase $\mathrm{B}$ and $\mathrm{C}$ are not affected.

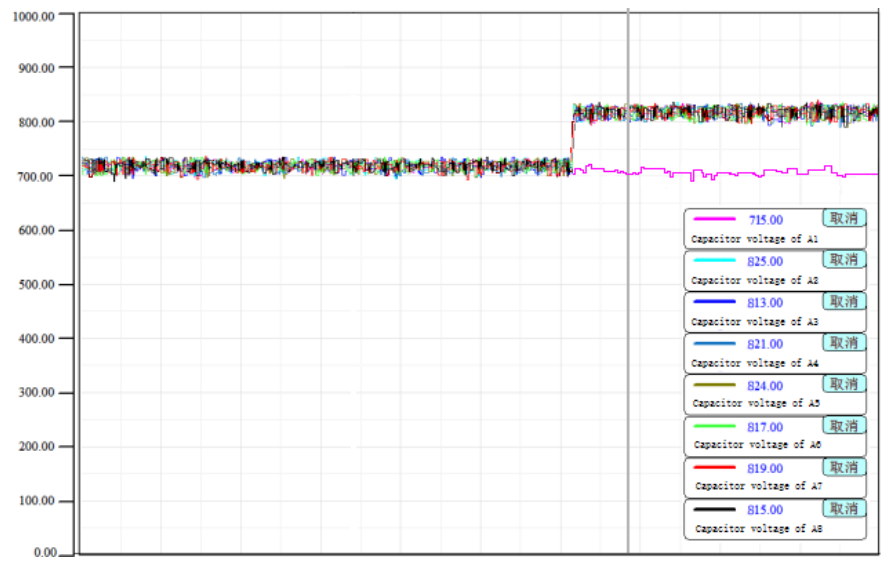

Figure 14. Waveforms of Capacitor Voltages of All Power Modules in Phase A

\section{Conclusion}

For the requirement of short-term stable operation of cascade STATCOM under fault condition, the influence of module fault on each control section is analyzed and the capacitor voltage balance control and PWM control strategies with fault-tolerant are proposed in this paper. The stable output voltage is ensured when fault occurs. The experiment verified the advantages of this method as manifested in the following aspects:

1. Avoid the wasting of two normal power modules in symmetric module isolation method.

2. The fault-tolerant control strategy is suitable for more than one fault modules.

3. Fast response speed, smooth transition process and less impact to power grid. 
4. Low requirement of fault diagnosis, it only needs to diagnose the fault module without a specific failure switch.

\section{References}

[1] J. Huang, "The Engineering Practice of \pm 200 Mvar STATCOM in China Southern Power Grid", Southern Power System Technology, vol. 6, no. 2, (2012), pp. 14-20.

[2] S. Xu, M. Chen, C. Fu, H. Zhang, X. Li, M. Li and Y. Wu, "The System Commissioning of \pm 200 Mvar STATCOM in China Southern Power Grid”, Southern Power System Technology, vol. 6, no. 2, (2012), pp. 21-25.

[3] W. Song and A. Q. Huang, "Fault-tolerant design and control strategy for cascaded H-bridge multilevel converter-based STATCOM", IEEE Transactions On Industrial Electronics, vol. 57, no. 8, (2010), pp. 2700-2708.

[4] P. W. Hammond, "Enhancing the reliability of modular medium-voltage drives", IEEE Transactions on Industrial Electronics, vol. 49, no. 5, (2002), pp. 948-954.

[5] J. Rodriguez, P. W. Hammond and J. Pontt, "Operation of a medium-voltage drive under faulty conditions", IEEE Transactions on Industrial Electronics, vol. 52, no. 5, (2005), pp. 1080-1085.

[6] Y. Zang, X. Wang and B. Xu, "Fault-tolerant design for multilevel cascaded H-bridge inverter", ICEMI' Beijing, China, (2005) August 259-263.

[7] W. Sanmin, C. Liu, X. Sun and F. Li, "Control of cascaded H-bridge multi-level inverters in fault", Journal of Tsinghua University(Science and Technology), vol. 43, no. 3, (2003), pp. 369-372.

[8] S. Wei, F. Li and X. Sun, "Control method for cascaded H-bridge multilevel inverter with faulty power cells", IEEE APEC Conf. Rec., Miami, USA, (2003).

[9] G. Wang, C. Wang and J. Zhou, "Modulation of cascaded multilevel inverters with faulty cells based on carrier", Journal of Huazhong University of Science and Technology, vol. 33, no. 2, (2005), pp. 109-111.

[10] X. Wang, Z. Yi, B. Xu and J.-Q. Lin, "Research on Switch-based Control Method for Cascaded HBridge Inverter Failures", Proceedings of the CSEE, vol. 27, no. 7, (2007), pp. 76-81.

[11] X. Ni, J. Zhao, W. Cao, K. Sun and H. Huang, "Modulation Reconfiguration of Cascaded Multilevel Inverters Under Fault Condition”, Proceedings of the CSEE, vol. 30, no. 33, (2010), pp. 16-22.

\section{Authors}
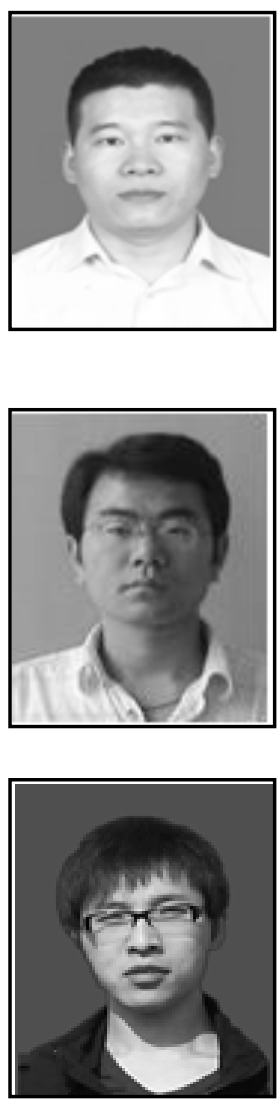

Xiaodong Yang, he received the $\mathrm{Ph} . \mathrm{D}$ degree in power electronics and power transmission from China University of Mining and Technology in 2014. He is now a college lecturer at School of Electrical Engineering in Yangcheng Institute of Technology. His research interests are fault diagnosis and fault-tolerant control of power electronics.

Zhenglong Xia, he received the $\mathrm{Ph} . \mathrm{D}$ degree in power electronics and power transmission from China University of Mining and Technology in 2014. He is now a college lecturer at School of Electrical Engineering and Automaion in Jiangsu Normal University. His research interests are reactive compensation of power system, fault diagnosis, distributed parallel processing, and neural network.

Wen-Yong Duan, he received the $\mathrm{Ph} . \mathrm{D}$ degree in Control Science and Engineering from school of Automation, Nanjing University of Science and Technology, Nanjing, Jiangsu Province, China, in 2014. He is now a college lecturer at School of Electrical Engineering in Yangcheng Institute of Technology. His areas of interest include stability analysis and robust control of time-delay systems, singular systems and complex dynamic network systems. 


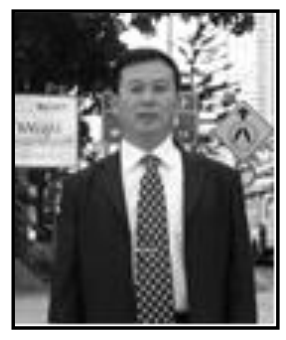

Guowen Hu, he is born in 1957, Ph.D. He is a professor at School of Electrical Engineering in Yangcheng Institute of Technology. His research interests are electrical safety and intelligent electrical apparatus. He has published more than 40 research papers in journals and international conferences. 
International Journal of Control and Automation

Vol. 10, No. 2 (2017) 